\title{
Multisensory numerosity judgments for visual and tactile stimuli
}

\author{
Alberto Gallace \\ Oxford University, Oxford, England \\ and Università degli Studi di Milano-Bicocca, Milan, Italy \\ Hong Z. TAN \\ Purdue University, West Lafayette, Indiana \\ AND \\ Charles Spence \\ Oxford University, Oxford, England
}

\begin{abstract}
To date, numerosity judgments have been studied only under conditions of unimodal stimulus presentation. It is therefore unclear whether the same limitations on correctly reporting the number of unimodal visual or tactile stimuli presented in a display might be expected under conditions in which participants have to count stimuli presented simultaneously in two or more different sensory modalities. In Experiment 1, we investigated numerosity judgments using both unimodal and bimodal displays consisting of one to six vibrotactile stimuli (presented over the body surface) and one to six visual stimuli (seen on the body via mirror reflection). Participants had to count the number of stimuli regardless of their modality of presentation. Bimodal numerosity judgments were significantly less accurate than predicted on the basis of an independent modality-specific resources account, thus showing that numerosity judgments might rely on a unitary amodal system instead. The results of a second experiment demonstrated that divided attention costs could not account for the poor performance in the bimodal conditions of Experiment 1. We discuss these results in relation to current theories of cross-modal integration and to the cognitive resources and/or common higher order spatial representations possibly accessed by both visual and tactile stimuli.
\end{abstract}

The majority of previous visual numerosity judgment studies have reported a difference in the accuracy and latency of people's enumeration responses to presentations of small versus large numbers of items (see, e.g., Atkinson, Campbell, \& Francis, 1976; Jevons, 1871; Trick \& Pylyshyn, 1993, 1994; Weiss, 1965). When the number of items presented is small (typically between one and four), the items appear to be processed very rapidly and nearly without error (see, e.g., Atkinson, Campbell, \& Francis, 1976). Increasing the number of items presented to more than four typically produces a large increase in both average response latencies and error rates, often giving rise to a discontinuity in the slope of the response latency and error functions. Such results have been interpreted by many authors (e.g., Jensen, Reese, \& Reese, 1950; Kaufman, Lord, Reese, \& Volkmann, 1949; Mandler \& Shebo, 1982; Peterson \& Simon, 2000; Trick \& Pylyshyn, 1993; Wender \& Rothkegel, 2000) as providing evidence for the existence of two qualitatively different enumeration processes: subitizing, which is specialized for small numbers of items, and counting, which is specialized for larger numbers of items. Subitizing is fast, accurate, and preattentive, whereas counting tends to be slow, error prone, and attention demanding.

Numerosity judgments have been studied outside of the visual modality as well. For example, ten Hoopen and Vos (1979) demonstrated that a distinction between subitizing and counting can be observed when people enumerate auditory stimuli (see also Cheatham \& White, 1954; Garner, 1951; Taubman, 1950; White \& Cheatham, 1959). However, the fact that the stimuli in ten Hoopen and Vos's research were presented sequentially makes any direct comparison with the results of previous visual numerosity judgment studies, in which the stimuli were nearly always presented simultaneously (though see Hill, 1971; Lechelt, 1975; and Viviani, 1979, for exceptions), difficult. Kashino and Hirahara (1996) presented different numbers of voices simultaneously and found that the accuracy of participants' estimates of the number of speakers was nearly perfect for up to two talkers but deteriorated substantially whenever three or more talkers were presented.

Finally, numerosity judgments have also been studied within the tactile modality. For example, Gallace, Tan, and Spence (2006c) found that the accuracy of partici-

A. Gallace, alberto.gallace@psy.ox.ac.uk 
pants' numerosity judgments when counting up to seven simultaneous vibrotactile stimuli distributed across their body surface decreased linearly as the number of stimuli increased, with no clear distinction between counting and subitizing evident (see also Lechelt, 1974, 1975, for the results of tactile serial numerosity judgment experiments). Moreover, error rates in Gallace et al.'s study became very high (i.e., $>30 \%$ ) whenever more than two tactile stimuli were presented (see also Alluisi, Morgan, \& Hawkes, 1965; Gallace, Tan, \& Spence, 2006d; Geldard \& Sherrick, 1965; Lechelt, 1975; Posey \& James, 1976; cf. Riggs et al., 2006).

It is important to note that Gallace et al.'s (2006c) results do not simply reflect some sort of sensory funneling effect (see von Békésy, 1959). ${ }^{1}$ Sensory funneling occurs only when the stimuli are located close together (i.e., with interstimulus spacings of no more than $2-3 \mathrm{~cm}$ ) and not when the interstimulus spacings are larger, as were those used in our previous experiment (cf. Gallace et al., 2006c, in which the smallest interstimulus spacing was around $20 \mathrm{~cm}$, as in the present study).

Although the PsycINFO database shows that approximately 150 unimodal numerosity judgment studies have been published to date, no previous study has attempted to investigate cross-modal numerosity judgments under conditions in which the stimuli to be counted are presented in more than one sensory modality (e.g., in both vision and touch; see Figure 1). However, we believe that investigation of the constraints limiting a person's ability to enumerate stimuli presented in more than one sensory modality warrant investigation. The results of such an investigation should provide important clues as to the level of information processing (and neural representation) at which the limitation in cognitive processing for numerosity judgments occurs (see, e.g., Dehaene \& Changeux, 1993; Jordan \& Brannon, 2006).

Various predictions can be made about the results that would be expected under conditions of multisensory stimulus presentation: (1) Performance in numerosity judgment tasks involving bimodal stimulus displays may reflect the sum of the performance limitations obtained in each of the unimodal stimulus displays (see Figure 2). This prediction follows from the view that the limitations on the processing of numerosity are modality specific. The idea here is that there may be several separate unimodal processing resources available for the enumeration of stimuli, one for stimuli presented in each sensory modality (cf. Duncan, Martens, \& Ward, 1997; Hein, Parr, \& Duncan, 2006; Martin, 1980; Navon \& Gopher, 1979; Soto-Faraco \& Spence, 2002; Wickens, 1980, 2002). (2) Limits on bimodal numerosity judgments would be no higher than the limits ascertained by studies of enumeration for particular sensory modalities (vision and touch) when those modalities are studied in isolation (see Figure 2). This prediction follows from the idea that a common pool of resources may be used when making numerosity judgments, regardless of the modality in which the stimuli happen to be presented. In this case, the processing limitations may correspond to an average of the limits reported for each sensory modality when observed in isolation (i.e., an average of a

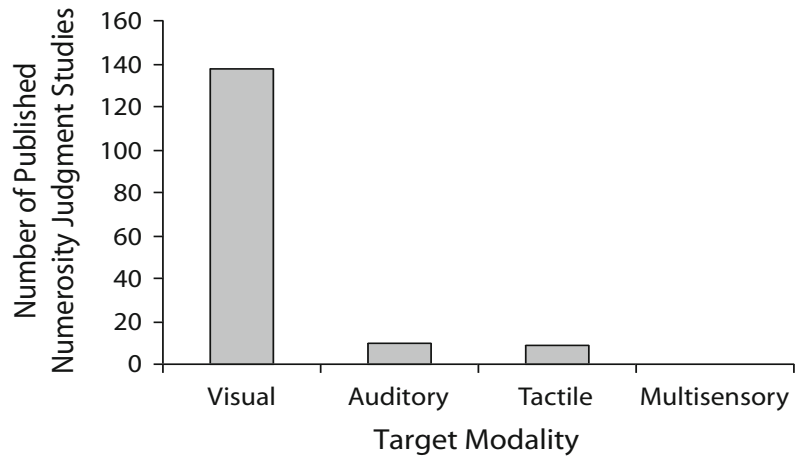

Figure 1. Approximate number of studies published on numerosity judgments for each sensory modality (i.e., vision, audition, and touch) up to 2006. Note that no study has yet been published on multisensory numerosity judgments.

higher limit, such as that reported for vision, and a lower limit, such as that reported for touch).

In the last few years, researchers have argued that inputs from different sensory modalities can interact at a number of different stages of neural processing and that certain cognitive systems, such as the one thought to control the allocation of spatial attention and those sustaining neural representations of space, may be multisensorially constrained (e.g., Driver \& Spence, 1998; Spence \& Driver, 2004). Therefore, it is possible that the information-processing constraints that limit performance under conditions of multisensory stimulus presentation may not simply reflect the sum of the limitations observed under conditions of unimodal stimulus presentation. For example, it may be that dividing attention between two or more sensory modalities can lead to worse performance than when attention is focused on a single sensory modality (see, e.g., Spence, Nicholls, \& Driver, 2001; Spence, Shore, \& Klein, 2001). However, with regard to this latter point, it should be noted that subitizing is thought to reflect a preattentive process, and so one might also predict that no such divided attention deficit should affect subitizing performance.

Interestingly, studies on animals have shown that rats and others mammals can add together sounds and visual stimuli and that monkeys spontaneously match the number of conspecific faces they see with the number of conspecific voices they hear (see, e.g., Church \& Meck, 1984; Jordan, Brannon, Logothetis, \& Ghazanfar, 2005; McComb, Packer, \& Pusey, 1994). Similar patterns of behavior have also been reported in both human adults and infants, suggesting that numerical nonverbal representations might be multisensory in both human and nonhuman animals (see, e.g., Jordan \& Brannon, 2006; Kobayashi, Hiraki, \& Hasegawa, 2005; Starkey, Spelke, \& Gelman, 1990; see also Eger, Sterzer, Russ, Giraud, \& Kleinschmidt, 2003; Hubbard, Piazza, Pinel, \& Dehaene, 2005; and Nieder, 2004, for the possible neurological substrates of such amodal numerical representations).

If the results of the present experiments show that the limits on bimodal numerosity judgments are worse than the sum of the limits obtained under conditions of uni- 


\section{Capacity limit for visual numerosity judgments}



Capacity limit for visuotactile

numerosity judgments

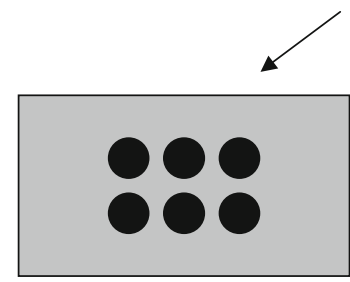

Additive model

(involving independent

resources) numerosity judgments
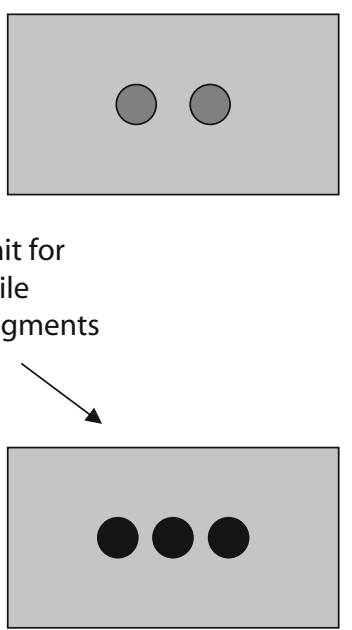

Amodal resource model (involving a common

pool of shared resources)
Capacity limit for tactile

Figure 2. Schematic representation of two possible accounts of numerosity judgment performance in Experiment 1 on the basis of two alternative models (i.e., independent vs. amodal resources). Capacity limits for unimodal judgments are represented by circles of different shades for each sensory modality. Note that capacity limits are lower for touch than for vision (see, e.g., Atkinson, Campbell, \& Francis, 1976; Gallace et al., 2006c). It is also important to note that the capacity limit predicted on the basis of a shared resources model represents the average of the means of the capacity limits of each of the two sensory modalities (i.e., three items). This limit may also correspond to the limit of one of the two sensory modalities- that is, the lowest limit (touch: two items) or the highest limit (vision: four items), but it will never be higher than the limit of the sensory modality with the highest capacity limit (i.e., never greater than four items).

modal stimulus presentation, then this may suggest that the processing of spatial numerosity occurs at a higherprobably an amodal or multisensory - level of information processing and/or neural representation (see White, Cheatham, \& Armington, 1953, for an early attempt to investigate the point at which the limitations in visual numerosity judgments occur).

It is also possible that the limit on bimodal numerosity judgments is actually somewhat higher than the limit that has been estimated from unimodal numerosity judgments. This outcome would be expected if the systems (and/or representations) involved in making numerosity judgments for visual and tactile stimuli were entirely independent (i.e., "encapsulated"; see Fodor, 1983). Under such conditions, the modality of stimulus presentation might actually provide an additional (and redundant) cue with which to make numerosity judgments in the bimodal condition (i.e., once participants realize that stimuli have been presented in two different sensory modalities, they should already know that the minimum number of stimuli that have been presented is two). Indeed, it has been demonstrated previously that making stimuli in unimodal visual numerosity displays more discriminable (e.g., by increasing the spatial separation between the stimuli in an array; Atkinson, Campbell, \& Francis, 1976) can improve performance in numerosity judgment tasks.

In the experiments reported here, we presented various numbers of visual and tactile stimuli distributed over the body surface and asked participants to count the total number of items that were presented regardless of the sensory modality of their occurrence. In Experiment 1, we presented both unimodal visual and tactile displays as well as bimodal displays consisting of various numbers of visual and tactile stimuli presented simultaneously.

\section{EXPERIMENT 1}

\section{Method}

Participants. Fourteen right-handed participants ( 6 males and 8 females) took part in this experiment as paid volunteers (mean age of 25 years; range, 19-33 years). All of the participants reported normal tactile perception and normal or corrected-to-normal vision. The experiment took approximately $20 \mathrm{~min}$ to complete and the participants received a $£ 5$ gift voucher in return for their participation. The experiments were noninvasive, had ethical approval from the Department of Experimental Psychology, University of Oxford, and were performed in accordance with the ethical standards laid down in the 1991 Declaration of Helsinki.

Apparatus and Materials. Participants sat on a chair for the duration of the experiment. The vibrotactile stimuli were presented by means of seven resonant-type tactors (VBW32, Audiological Engineering Corp., Somerville, MA) with $1.6 \times 2.4 \mathrm{~cm}$ vibrating surfaces. The tactors were placed on the participants' bodies on top of any clothing they happened to be wearing, by means of Velcro strip belts. Green LEDs were mounted at the same position as each tactor but on the other side of the belts (see Figure 3 for the position of the tactors and LEDs on the body; cf. Gallace, Tan, \& Spence, 2005). The vibrators were driven by means of a custom-built ninechannel amplifier circuit (Haptic Interface Research Laboratory, Purdue University) that drove each tactor independently at $290 \mathrm{~Hz}$ (close to its resonant frequency). The LEDs were driven by means of a custom-built relay box.

The activation of each tactor and LED was controlled through the serial and parallel ports of a laptop computer running custom software written in MATLAB 6.0. The intensity of each tactor was adjusted individually at the beginning of the experiment so that each vibrotactile stimulus could be perceived clearly, and all of the tactile stimuli were perceived to be of a similar intensity. The amplification levels for the tactors were kept at their individually chosen levels throughout the experiment. White noise was presented over closed-ear headphones at $70 \mathrm{~dB}(\mathrm{~A})$ to mask any sounds made by the operation of the vibrotactile stimulators and relay box. A $65 \times 90 \mathrm{~cm}$ mirror was placed $100 \mathrm{~cm}$ in front of each participant (measured from the upper edge of the mirror to the participant's eyes). The participants were able to see the visual stimuli on their bodies by means of the mirror's reflection. We used mirror reflection rather than direct observation of the participant's own body in order to maximize the comfort of our participants and also to allow direct comparison with previously published studies in which the same means of stimulus presentation was adopted (see, e.g., Gallace, Auvray, Tan, \& Spence, 2006). The ability of participants to correctly discriminate the visual stimuli presented from each body location was confirmed at the beginning of the experiment for each participant.

There were four different conditions: unimodal visual, unimodal tactile, bimodal overlapping, and bimodal nonoverlapping. In the unimodal conditions, one to six LEDs (unimodal visual condition) or tactors (unimodal tactile condition) were randomly activated on each trial. For each number of stimuli presented, different patterns 


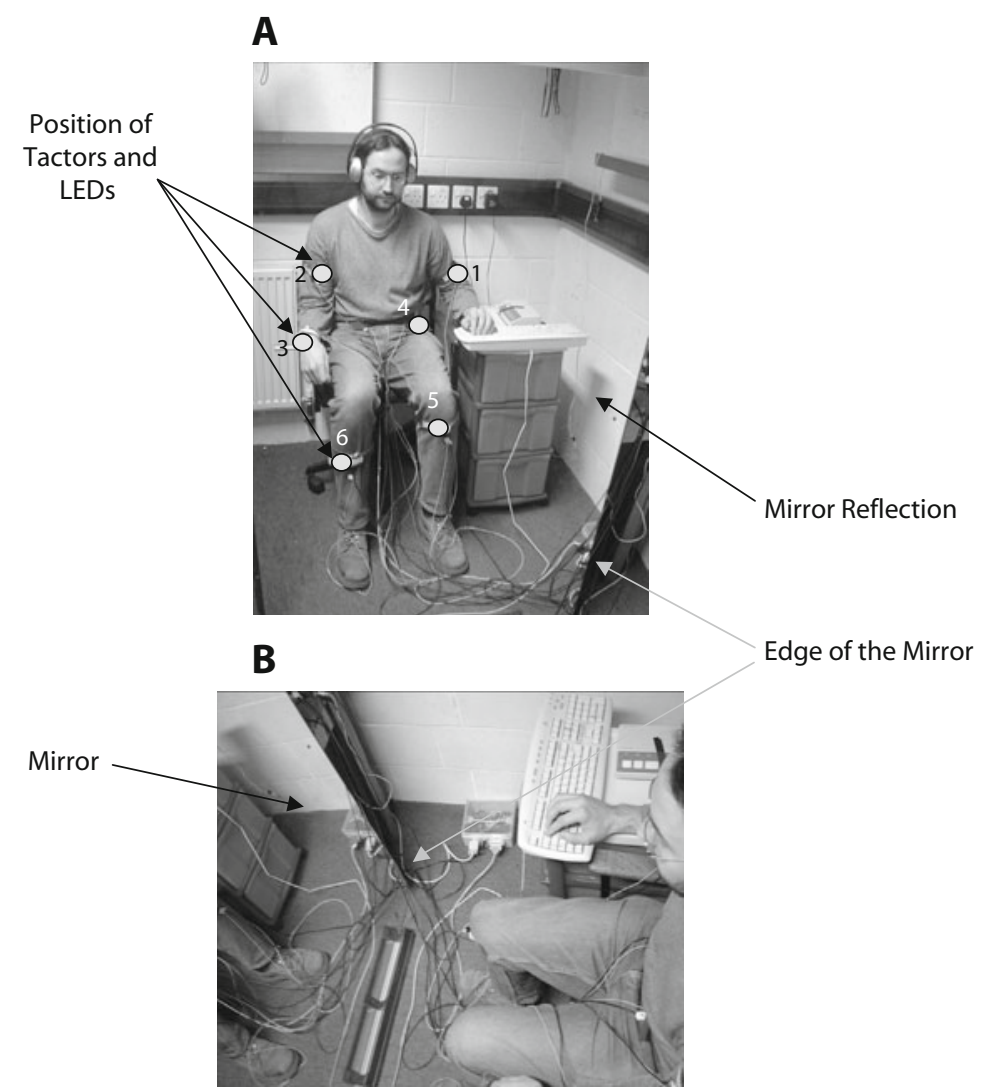

Figure 3. Experimental setup used in Experiments 1 and 2. (A) Locations of tactors on the body surface: (1) just above the right elbow; (2) midway between the elbow and the shoulder of the left arm; (3) left wrist; (4) on the waistline to the right of the body midline; (5) just below the right knee; and (6) midway between the ankle and knee of the left leg. Note that these positions were chosen to ensure that homologous sites on both sides of the body were never stimulated. (B) Position of the participant in front of the mirror.

of activation (i.e., configurations of tactors or LEDs) were chosen randomly from among all of the possible combinations. In the bimodal conditions, two to six tactile and visual stimuli were randomly presented at the same time (see Table 1 for the number of tactile and visual stimuli making up each display). In the overlapping condition, the visual and tactile stimuli were presented from the same position on at least one body location. In the nonoverlapping condition, the visual and tactile stimuli were always presented from different body positions (see Figure 4). Participants were asked to look at a central position in the mirror, but no fixation point was provided. Each display was presented for $200 \mathrm{msec}$ and the intertrial interval (i.e., the time between the participant's response, or the end of the trial if no response was given within $4 \mathrm{sec}$, and the beginning of the next trial) was $800 \mathrm{msec}$

Procedure. The participants were instructed to press the numerical key on a computer keyboard that corresponded to the absolute number of stimuli they perceived on each trial, regardless of the sensory modality in which the stimuli were presented. The participants were instructed to respond as accurately as possible. They were also informed that each trial would be terminated after the participant's response or after $4 \mathrm{sec}$ had elapsed from the onset of the stimulus display. The experiment was divided into three equal-length blocks

Table 1

Composition of the Displays Presented in the Bimodal Condition for Each Numerosity, and Frequency With Which Each Pattern Was Presented in Experiment 1

\begin{tabular}{|c|c|c|c|c|c|c|c|c|c|c|}
\hline \multirow[b]{3}{*}{ Pattern } & \multicolumn{10}{|c|}{ Numerosity of Display } \\
\hline & \multicolumn{2}{|c|}{$N=2$} & \multicolumn{2}{|c|}{$N=3$} & \multicolumn{2}{|c|}{$N=4$} & \multicolumn{2}{|c|}{$N=5$} & \multicolumn{2}{|c|}{$N=6$} \\
\hline & Comp & $\overline{\text { Freq }}$ & Comp & Freq & Comp & Freq & Comp & Freq & Comp & Freq \\
\hline 1 & $1 \mathrm{~V}, 1 \mathrm{~T}$ & 12 & $2 \mathrm{~V}, 1 \mathrm{~T}$ & 6 & $3 \mathrm{~T}, 1 \mathrm{~V}$ & 4 & $3 \mathrm{~T}, 2 \mathrm{~V}$ & 6 & $4 \mathrm{~T}, 2 \mathrm{~V}$ & 4 \\
\hline 2 & & & $1 \mathrm{~V}, 2 \mathrm{~T}$ & 6 & $3 \mathrm{~V}, 1 \mathrm{~T}$ & 4 & $2 \mathrm{~V}, 3 \mathrm{~T}$ & 6 & $2 \mathrm{~V}, 4 \mathrm{~T}$ & 4 \\
\hline 3 & & & & & $2 \mathrm{~V}, 2 \mathrm{~T}$ & 4 & & & $3 \mathrm{~V}, 3 \mathrm{~T}$ & 4 \\
\hline
\end{tabular}

Note-For numerosity values greater than 2 , more than one pattern of stimulation was presented. $N$, number of stimuli; Comp, composition; Freq, frequency; V, visual; T, tactile. 


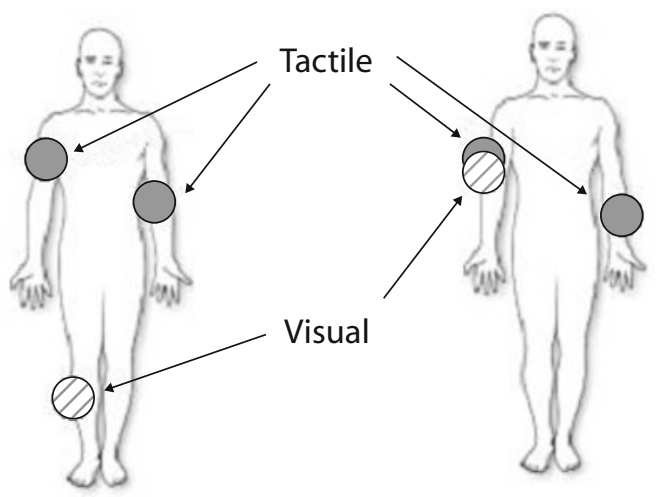

Figure 4. Examples of the nonoverlapping (left) and overlapping (right) stimulus conditions in Experiment 1 for the case of three stimuli.

of trials separated by short breaks. Twelve stimuli were presented for each numerosity and in each condition (in the unimodal presentation conditions, 24 stimuli were presented for conditions in which numerosity was one; see Table 1 for the number of stimuli presented in each modality and for each numerosity), giving rise to a total of 288 trials completed by each participant. The participants were not informed of the maximum number of stimuli that could be presented in any trial. Two experimental sessions were performed, one in which the experiment was conducted under normal illumination conditions (i.e., with the room lights on) and the other in which the experiment was conducted in complete darkness (in this session, the participants were not able to see their own images reflected on the screen but only the reflection of the LEDs). The lights off session was conducted in order to explore whether any interactions among visuotactile numerosity judgments might be related to the visual capture of the perceived location of tactile stimuli that might have resulted from participants' seeing their own bodies reflected in the mirror (see, e.g., Gallace \& Spence, 2005; Maravita, Spence, Sergent, \& Driver, 2002; Sathian, Greenspan, \& Wolf, 2000; Whiteley, Kennett, Taylor-Clarke, \& Haggard, 2004). The order of presentation of the two sessions was counterbalanced across participants.

\section{Results}

For each participant, the percentage of errors for each number of stimuli presented in any of the experimental conditions was determined. Trials in which participants failed to give a response within $4 \mathrm{sec}$ of stimulus onset were not included in any of the data analyses (resulting in the removal of less than $1 \%$ of trials overall). The accuracy data were submitted to a repeated measures ANOVA with the factor of numerosity (five levels: two to six stimuli presented; note that trials in which only one stimulus was presented were not analyzed, because there was no equivalent condition in the bimodal blocks of trials; note also that performance in this condition was near perfect, with $3.8 \%$ and $2.3 \%$ errors for displays composed of a single tactile stimulus and a visual unimodal stimulus, respectively), lighting (lights on vs. lights off), and modality (unimodal vs. bimodal).

The analysis of the accuracy data revealed significant main effects of numerosity $[F(4,52)=149.2, p<.0001]$ and modality $[F(1,13)=26.1, p<.001]$, but not of lighting $[F(1,13)=2.88$, n.s. $]$. The number of errors increased as the number of stimuli presented increased, and perfor- mance was worse in the bimodal conditions than in the unimodal conditions (see Figures 5A and 5B). There was also a significant interaction between numerosity and modality $[F(4,52)=10.5, p<.0001]$. A Duncan post hoc test revealed significant differences between the unimodal and bimodal conditions when three, four, five, or six stimuli were presented $(p<.001, p<.05, p<.0001$, and $p<$ .001 , respectively), but not when only two stimuli were presented ( $p=.30$, n.s.).

A second analysis was conducted in order to compare the performance expected in the bimodal trials (assuming that the processing of visual and tactile stimuli relied on independent pools of resources) with the actual pattern of performance obtained. In order to compute the expected performance, the sum of errors made in the unimodal trials was calculated as a function of the equivalent number of visual and tactile stimuli making up the display. For example, for the bimodal displays composed of three stimuli, two different equiprobable display patterns were used (see Table 1 for the different display patterns used in each numerosity condition). One of the displays was composed of one visual stimulus and two tactile stimuli and the other of two visual stimuli and one tactile stimulus. Therefore, for bimodal numerosity judgments of displays composed of three stimuli, the expected level of performance was calculated as follows: The errors in the unimodal trials obtained with displays composed of one visual stimulus and the errors obtained with displays composed of two tactile stimuli were added (this provided an estimate of the total number of errors expected for the first of the two alternative display patterns). The errors in the unimodal trials obtained with displays composed of two visual stimuli and the errors obtained with displays composed of one tactile stimulus were also added (this result provided an estimate of the total number of errors expected for the second of the two alternative display patterns). These two values were then added, and the total was divided by two, given that the two display patterns were presented equiprobably. The result provided an estimate of the number of errors expected in bimodal display trials composed of three stimuli.

The numbers of expected and obtained errors were calculated for each participant for both experimental sessions. These measures were submitted to two separate ANOVAs with the factors of numerosity (two to six) and data model (expected vs. obtained). The analysis of the lights on data revealed significant main effects of numerosity $[F(4,52)=$ $173.9, p<.0001]$ and data model $[F(1,13)=51.7, p<$ $.0001]$, as well as a significant interaction between these two factors $[F(4,52)=5.3, p<.005]$. A Duncan post hoc test on the interaction revealed significant differences between the expected and obtained data for each level of the numerosity factor. Numerically larger differences between the two conditions were reported for three, five, and six stimuli, and smaller differences were reported for two and four stimuli (see Figure 5). The analysis of the lights off data revealed significant main effects of numerosity $[F(4,52)=224.2$, $p<.0001]$ and data model $[F(1,13)=14.1, p<.005]$ and a borderline significant interaction between these two factors $[F(4,52)=2.5, p=.056]$. A Duncan post hoc test again revealed significant differences between the expected 

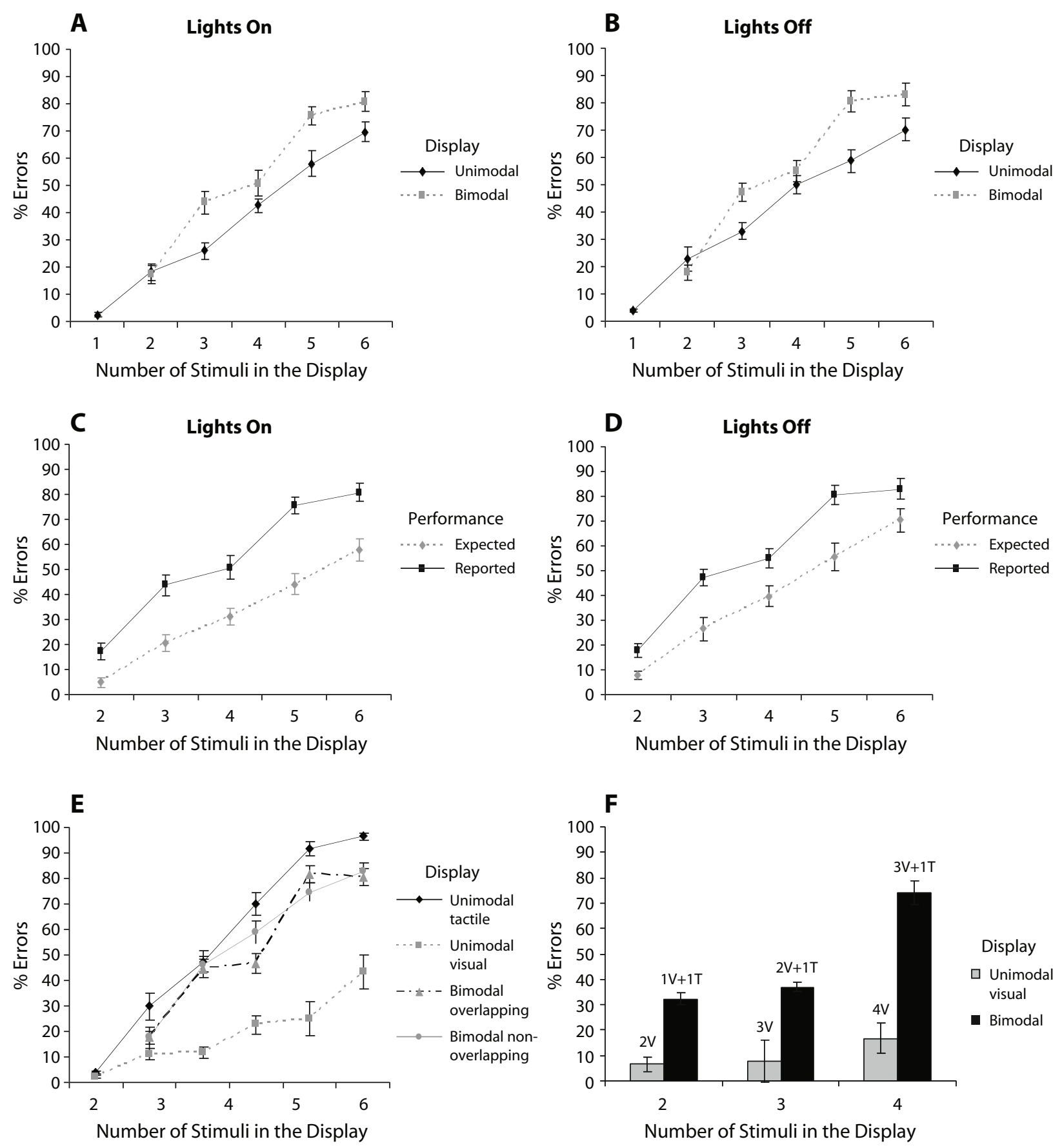

Figure 5. Participants' performance in Experiment 1. Panels $A$ and $B$ show the mean error rates as a function of the number of stimuli presented in the display for the unimodal and bimodal displays in the lights on and lights off sessions, respectively. Panels $\mathrm{C}$ and $D$ show the mean expected and reported percentages of errors as a function of the number of stimuli presented in the display in the lights on and lights off sessions, respectively. Panel $E$ shows the mean error rates as a function of the number of stimuli presented in the display for all experimental conditions. Panel F shows the mean error rates in the lights on condition as a function of the number of stimuli presented in the display for different displays. The numbers of visual $(V)$ and tactile $(T)$ stimuli presented in the displays are represented above each bar. Error bars represent the standard errors of the means.

and obtained data for each level of the numerosity factor. Numerically larger differences between the two conditions were reported for three, five, and six stimuli, and smaller differences were reported when either two or four stimuli were presented (see Figures 5C and 5D).
The data concerning the percentage of errors in each experimental condition were further explored using an ANOVA with the factors of modality (four levels: visual, tactile, bimodal overlapping, and bimodal nonoverlapping) and numerosity (two to six stimuli). Given that the 
difference between the lights on and lights off sessions did not result in any significant differences in our initial analysis, the data obtained from these two sessions were collapsed. The new analysis revealed significant main effects of modality $[F(3,39)=108.7, p<.0001]$ and numerosity $[F(4,52)=149.2, p<.0001]$, as well as a significant interaction between these two factors $[F(12,156)=9.32, p<.0001]$. A Duncan post hoc test on the main effect of modality revealed significant differences among all of the experimental conditions (all $p$ s $<.001)$, except between the bimodal overlapping and nonoverlapping conditions ( $p=.47$, n.s.). The best performance was reported in the unimodal visual condition and the worst performance in the unimodal tactile condition. A Duncan post hoc test on the interaction between numerosity and modality revealed significant differences between the unimodal tactile and unimodal visual conditions at each level of the numerosity factor (all $p$ s $<$ .001 ), significant differences among the unimodal visual and the two bimodal conditions for all of the numerosity values except two (all $p \mathrm{~s}<.001$ ), and significant differences between the unimodal tactile condition and the two bimodal conditions for all numerosities except three (all $p$ s $<.05$; see Figure 5E; see Tables 2 and 3 for the confusion matrices of the participants' responses to the various displays; cf. Gallace et al., 2006c).

A further analysis was performed on the error data from the lights on condition in order to explore whether participants' performance in the bimodal displays in which the available cues regarding numerosity were redundant (i.e., for conditions in which stimuli were presented in two different sensory modalities such that, once participants realized this, they should already have known that the minimum number of stimuli presented was two). The percentage of errors in participants' numerosity judgments was explored using an ANOVA with the factors of modality (unimodal visual vs. bimodal) and numerosity (2 to 4 ). The results of this analysis revealed significant main effects of both modality $[F(1,13)=76.7, p<.0001]$ and numerosity $[F(2,26)=15.5, p<.0001]$, as well as a significant interaction between these two factors $[F(2,26)=$ $9.12, p<.0001]$. Once again, numerosity judgments for the bimodal stimulation conditions were worse than those for the unimodal visual conditions, showing that when redundant cues were provided, bimodal numerosity judgments were worse (see Figure 5F).

This result might be related to the influence of the Colavita effect (i.e., the frequent failure by participants to identify an auditory stimulus when it is presented at the same time as a visual stimulus to which they also have to respond; see Colavita, 1974; Sinnett, Spence, \& SotoFaraco, in press) on visuotactile processing. (Note that although the Colavita effect has only been demonstrated using audiovisual displays, there is no theoretical reason that it should not extend to the visual-tactile modality pairing as well; see Gallace, Krings, Koppen, \& Spence, 2007.) In other words, visual stimuli might, at least in part, dominate over the judgments of the number of stimuli comprising the bimodal displays, or rather the simultane-
Table 2

Confusion Matrices for the Lights On Condition of Experiment 1, Highlighting the Percentage of Times Participants Made Each of the Given Responses When a Given Number of Vibrotactile Stimuli Were Activated

\begin{tabular}{|c|c|c|c|c|c|c|}
\hline \multirow[b]{2}{*}{ No. Stimuli } & \multicolumn{6}{|c|}{ Response } \\
\hline & 1 & 2 & 3 & 4 & 5 & 6 \\
\hline \multicolumn{7}{|c|}{ Unimodal Tactile } \\
\hline 1 & 97.2 & 2.1 & 0.3 & 0.0 & 0.0 & 0.0 \\
\hline 2 & 7.6 & 71.5 & 19.4 & 0.7 & 0.7 & 0.0 \\
\hline 3 & 0.0 & 29.2 & 61.8 & 8.3 & 0.7 & 0.0 \\
\hline 4 & 0.7 & 9.0 & 47.9 & 32.6 & 7.6 & 0.7 \\
\hline 5 & 0.0 & 8.3 & 47.2 & 33.3 & 10.4 & 0.7 \\
\hline 6 & 0.0 & 2.8 & 31.3 & 42.4 & 16.7 & 6.9 \\
\hline \multicolumn{7}{|c|}{ Unimodal Visual } \\
\hline 1 & 97.2 & 2.1 & 0.3 & 0.0 & 0.0 & 0.0 \\
\hline 2 & 2.8 & 95.1 & 2.1 & 0.0 & 0.0 & 0.0 \\
\hline 3 & 0.0 & 4.9 & 93.1 & 1.4 & 0.0 & 0.0 \\
\hline 4 & 0.0 & 0.0 & 9.0 & 86.8 & 4.2 & 0.0 \\
\hline 5 & 0.0 & 0.0 & 2.8 & 22.2 & 68.8 & 3.5 \\
\hline 6 & 0.7 & 0.0 & 1.4 & 11.1 & 26.4 & 53.5 \\
\hline \multicolumn{7}{|c|}{ Bimodal Overlapping } \\
\hline 2 & - & 79.9 & 1.4 & 1.4 & 0.0 & 0.0 \\
\hline 3 & - & 30.6 & 61.1 & 6.3 & 0.7 & 0.0 \\
\hline 4 & - & 9.0 & 29.9 & 59.0 & 2.1 & 0.0 \\
\hline 5 & - & 2.1 & 22.2 & 44.4 & 26.4 & 4.9 \\
\hline 6 & - & 0.0 & 9.0 & 31.9 & 35.4 & 20.1 \\
\hline \multicolumn{7}{|c|}{ Bimodal Nonoverlapping } \\
\hline 2 & - & 84.7 & 8.3 & 0.7 & 0.0 & 0.0 \\
\hline 3 & - & 37.5 & 52.8 & 6.3 & 0.7 & 0.0 \\
\hline 4 & - & 8.3 & 41.7 & 44.4 & 3.5 & 0.7 \\
\hline 5 & - & 6.3 & 18.8 & 44.4 & 27.1 & 2.8 \\
\hline 6 & - & 0.0 & 11.8 & 30.6 & 38.9 & 16.7 \\
\hline
\end{tabular}

Note-Responses exceeding the maximum number of stimuli presented in the display ( $<5 \%$ of responses overall) are not reported in the table. Numbers in boldface represent the percentages of correct responses.

ous presentation of visual stimuli might to some extent extinguish a participant's awareness of the tactile stimuli (see Vallar, Rusconi, Bignamini, Geminiani, \& Perani, 1994; Vuilleumier \& Rafal, 2000).

In order to further explore the modulatory effect that visual stimuli might exert over participants' responses, participants' mean numerosity judgments for the various displays were correlated with the percentage of stimuli presented in each sensory modality (see Figure 6). Visual inspection of Figure 6 shows that participants' responses to the various displays were modulated by the percentage of visual stimuli in the displays (i.e., the magnitude of participants' mean numerosity judgments increased as the proportion of visual stimuli in the display increased) for displays of four or more stimuli. This result, and the observation that the slopes of the lines fitting the response data were quite shallow (i.e., the participants' numerosity judgments did not show particularly large changes as the number of visual stimuli in the display increased; see Table 4 for the best-fitting equations for the data functions) suggest that visual dominance by itself (in the form of a putative Colavita effect) is not sufficient to explain the results of our experiment. 
Table 3

Confusion Matrices for the Lights Off Condition of Experiment 1, Highlighting the Percentage of Times Participants Made Each of the Given Responses When a Given Number of Vibrotactile Stimulators Were Activated

\begin{tabular}{|c|c|c|c|c|c|c|}
\hline \multirow[b]{2}{*}{ No. Stimuli } & \multicolumn{6}{|c|}{ Response } \\
\hline & 1 & 2 & 3 & 4 & 5 & 6 \\
\hline \multicolumn{7}{|c|}{ Unimodal Tactile } \\
\hline 1 & 92.0 & 8.0 & 0.0 & 0.0 & 0.0 & 0.0 \\
\hline 2 & 9.6 & 72.3 & 14.5 & 1.2 & 0.0 & 0.0 \\
\hline 3 & 1.8 & 36.1 & 54.8 & 3.6 & 0.6 & 0.6 \\
\hline 4 & 0.0 & 9.0 & 55.4 & 30.1 & 3.0 & 0.0 \\
\hline 5 & 0.0 & 12.0 & 51.8 & 26.5 & 7.2 & 0.0 \\
\hline 6 & 0.0 & 1.2 & 43.4 & 36.1 & 12.0 & 3.0 \\
\hline \multicolumn{7}{|c|}{ Unimodal Visual } \\
\hline 1 & 92.9 & 6.5 & 0.0 & 0.0 & 0.0 & 0.0 \\
\hline 2 & 11.4 & 81.3 & 3.6 & 0.6 & 0.0 & 0.0 \\
\hline 3 & 2.4 & 6.0 & 82.5 & 6.6 & 0.0 & 0.0 \\
\hline 4 & 0.6 & 2.4 & 10.8 & 76.5 & 7.2 & 0.0 \\
\hline 5 & 0.6 & 0.6 & 1.8 & 9.6 & 83.1 & 1.2 \\
\hline 6 & 1.2 & 0.6 & 3.0 & 3.6 & 27.7 & $\mathbf{5 7 . 8}$ \\
\hline \multicolumn{7}{|c|}{ Bimodal Overlapping } \\
\hline 2 & & 84.9 & 3.0 & 0.0 & 0.0 & 0.0 \\
\hline 3 & & 32.5 & 56.6 & 4.8 & 0.6 & 0.6 \\
\hline 4 & & 10.2 & 30.7 & 52.4 & 2.4 & 0.0 \\
\hline 5 & & 2.4 & 22.9 & 46.4 & 22.3 & 3.0 \\
\hline 6 & & 3.0 & 9.6 & 29.5 & 31.9 & 23.5 \\
\hline \multicolumn{7}{|c|}{ Bimodal Nonoverlapping } \\
\hline 2 & & 78.3 & 8.4 & 0.0 & 0.0 & 0.0 \\
\hline 3 & & 42.2 & 51.2 & 3.0 & 0.0 & 0.0 \\
\hline 4 & & 11.4 & 35.5 & 46.4 & 3.0 & 0.0 \\
\hline 5 & & 3.6 & 23.5 & 41.6 & 27.1 & 1.8 \\
\hline 6 & & 3.0 & 11.4 & 24.7 & 34.3 & 22.9 \\
\hline
\end{tabular}

Note-Responses exceeding the maximum number of stimuli presented in the display ( $<5 \%$ of responses overall) are not reported in the table. Numbers in boldface represent the percentages of correct responses.

\section{Discussion}

The results of Experiment 1 show that participants' numerosity judgment performance on bimodal trials was not predictable on the basis of an independent resources model that was derived from the results obtained in the unimodal numerosity judgment trials. In fact, the mean percentage of errors in participants' numerosity judgments for bimodal stimulus displays (calculated as the average of the errors reported in the bimodal overlapping and nonoverlapping displays) was higher than the mean percentage of errors obtained for the unimodal displays (calculated as the average of the unimodal visual and tactile displays) when both types of display had the same actual numerosity. There was no significant difference in performance between bimodal overlapping and bimodal nonoverlapping trials. We thought it possible that the lack of any difference between these two conditions might be accounted for by the presence of a ventriloquism effect (i.e., the misperception of the location of a sound caused by the concurrent presentation of a visual stimulus; see Bertelson \& de Gelder, 2004, for a review) for tactile stimuli in the direction of simultaneously presented visual stimuli (see Spence, Pavani, $\&$ Driver, 2004). That is, the perceived location of any vibrotactile stimuli present in a display might have been misplaced toward the location of the nearest available visual stimulus, thus potentially eliminating any subjective differences between the overlapping and nonoverlapping patterns of stimulation. However, given that the stimuli were not seen directly but instead were seen via mirror reflection, it is also possible that the overlapping visual and tactile stimuli were never actually perceived as overlapping spatially, but merely as arising from similar (or, in some sense, corresponding) locations, again making the lack of any difference between the two conditions less surprising.

The main result to emerge from the analysis of Experiment 1 is that numerosity judgments for bimodal stimulus displays were significantly worse than those that were predicted on the basis of an entirely independent resources model (in which the limitation in numerosity judgments for bimodal displays would have been derived from the limitations obtained from the corresponding unimodal displays). This finding clearly supports the view that numerosity judgments might be based on a common cognitive system (i.e., neural representation) used for processing numerical information in both sensory modalities and/or the two sensory modalities investigated access a common pool of shared resources.

One possible cause for such poor performance may be related to the role played by focused (vs. divided) attention. Spence, Nicholls, and Driver (2001), in their study of selective attention to a specific sensory modality, demonstrated that speeded discrimination judgments regarding the location (left vs. right) of tactile targets presented within an unpredictable sequence of auditory, visual, and tactile targets were better (i.e., faster and more accurate) when attention could be directed toward the tactile modality in advance than when attention had to be divided between several sensory modalities simultaneously (see also Spence, Shore, \& Klein, 2001).

Experiment 2 was designed to explore further what role, if any, dividing attention between two different sensory modalities may have played in the pattern of results reported in Experiment 1. Participants in Experiment 2 had to determine the number of unimodal visual or tactile stimuli presented in the display under conditions of either focused or divided attention. In half of the blocks of trials (focused attention), the targets were always predictably presented in a single modality (either vision or touch), whereas in the remainder of the blocks (divided attention), the target modality was chosen randomly (and unpredictably) on a trial-by-trial basis. If dividing attention between two sensory modalities does indeed impair bimodal numerosity judgments, then one would expect performance to be significantly worse in the divided attention blocks than in the focused attention blocks.

\section{EXPERIMENT 2}

\section{Method}

Participants. Twelve right-handed participants ( 2 males and 10 females) took part in this experiment as volunteers (mean age, 20 years; range, $18-27$ years). All of the participants reported normal tactile perception and normal or corrected-to-normal vision. 


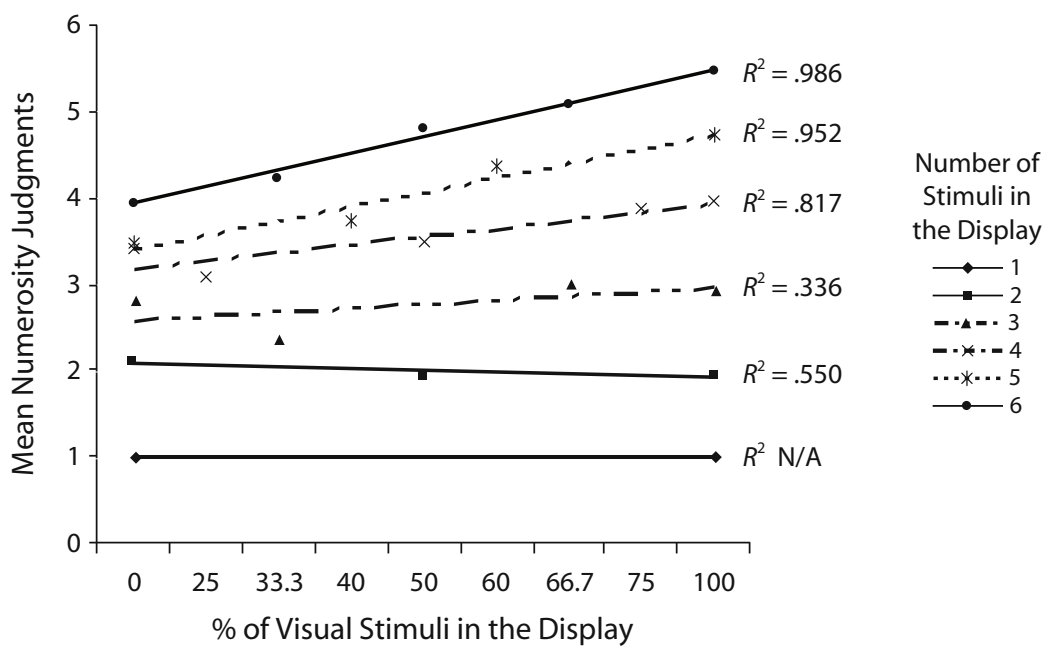

Figure 6. Mean numerosity judgments of participants as a function of the percentage of visual stimuli in the display for each level of numerosity. The best-fitting linear functions of the data and their coefficients of correlation $\left(R^{2}\right)$ are also presented.

The experiment took approximately 15 min to complete, and the participants received course credit in return for their participation.

Apparatus, Materials, Design, and Procedure. The experimental setup and procedure were exactly the same as in Experiment 1 , with the following exceptions: Bimodal stimulus displays were no longer presented. Instead, focused and divided attention conditions for the unimodally presented visual and tactile stimuli were presented. In the focused attention condition, the unimodal visual and tactile stimuli were presented in separate blocks of experimental trials, whereas in the divided attention condition, the unimodal visual and tactile stimuli were presented intermixed randomly within the same block of trials. The order of presentation of the three blocks of trials was randomized between participants. In both the focused and divided attention conditions, 72 visual and 72 tactile stimuli were presented, giving rise to a total of 288 trials for each participant.

\section{Results and Discussion}

For each participant, the percentage of errors for each display size in each of the experimental conditions was collected (see Figure 7). Trials in which participants failed to make a response within $4 \mathrm{sec}$ of stimulus onset (less than $1 \%$ of trials overall) were not included in any of the data analyses. The error data were submitted to a repeated measures ANOVA with the factors of numerosity (two to six), target modality (visual vs. tactile), and attention (focused vs. divided). This analysis revealed a significant main effect of numerosity $[F(5,55)=140.7, p<$ $.0001]$ and target modality $[F(1,11)=482.5, p<.0001]$ and a significant interaction between these two factors $[F(5,55)=74.2, p<.0001]$. Participants made far more errors in response to the tactile displays $(M=55.1 \%)$ than to the visual displays $(M=8.6 \%)$ overall, and the number of errors increased as the number of stimuli in the display increased. A Duncan post hoc test on the numerosity $X$ modality interaction revealed significant differences between tactile and visual stimuli when three to six stimuli were presented in the display (all $p$ s $<.001$ ) but not when only two stimuli were presented. There was no main effect of attention $[F(1,11)=2.7$, n.s.], and none of the other interactions reached significance.

The results of Experiment 2 show that forcing participants to divide their attention between touch and vision did not affect their performance in this unspeeded numerosity judgment task. That is, the same level of performance was reported under conditions of both focused $(M=32.8 \%)$ and divided $(M=30.9 \%)$ attention. Once again, the number of errors for both modalities increased as the number of stimuli presented in the display increased (cf. Atkinson, Campbell, \& Francis, 1976; Gallace et al., 2006c).

Interestingly, in Experiment 2 just as in Experiment 1, the number of errors in the numerosity judgment task was correlated with the number of stimuli presented for both the tactile and visual displays (see Figures 5E and 6). Although the same pattern of results was reported previously for vibrotactile stimuli distributed over the body surface (see Gallace et al., 2006c), the lack of a robust distinction between the subitizing and counting ranges when unimodal visual displays were presented is somewhat surprising. One possible explanation for such an effect is related to the large spacing between stimuli in our study; this large spacing may have required more cognitive resources or a larger shift of spatial attention (cf. Lakatos \& Shepard, 1997; Posner, 1980) to be correctly localized (note that

Table 4

Best-Fitting Equations for Participants' Percentages of Error and Responses in Each Condition of Experiment 1, for the Lights On and the Lights Off Conditions Together

\begin{tabular}{llc}
\hline \multicolumn{1}{c}{ Condition } & \multicolumn{1}{c}{ \% Error } & Response \\
\hline Unimodal tactile & $19.17 N-10.61$ & $.53 N^{*}+.89$ \\
Unimodal visual & $7.38 N-6.48$ & $.89 N^{*}+.21$ \\
Bimodal nonoverlapping & $15.95 N-7.73$ & $.65 N^{*}+.75$ \\
Bimodal overlapping & $16.31 N-11.01$ & $.53 N^{*}+.89$ \\
\hline
\end{tabular}

Note $-N=$ number of stimuli presented in the display; $N^{*}=$ number of stimuli presented in the display. 


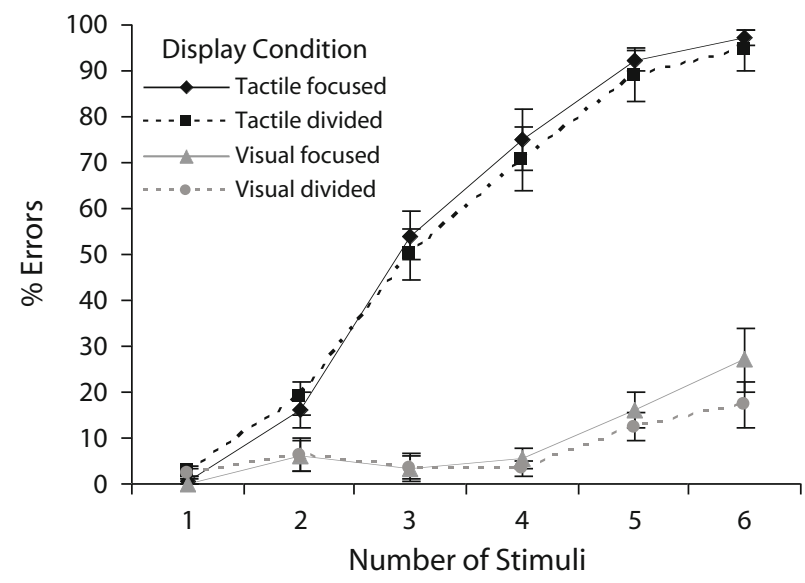

Figure 7. Mean error rates as a function of the modality of presentation (tactile or visual) and of the number of stimuli presented in the display for the focused and divided attention conditions in Experiment 2. Error bars represent the standard errors of the means.

all previous studies of visual numerosity judgments have presented stimuli only within the constraints of the screen of a computer monitor). Alternatively, it is possible that the large spacing used in the present experiment deleteriously affected the participants' ability to group the stimuli into recognizable patterns (see, e.g., Atkinson, Francis, \& Campbell, 1976), thus resulting in a reduction of any difference between the subitizing and counting ranges. Interestingly, it has been shown, using a relatively small display (covering no more than $3.8^{\circ}$ of visual angle), that a significant divergence from veridical responding occurs when more than six objects are presented visually at the same time (Lechelt, 1971). This result might be taken to support the view that the size of the display (or rather, the magnitude of the interstimulus spacing) may influence the number of stimuli that can be reported accurately at any one time.

However, it is also worth noting that a few researchers have argued against the separability of subitizing and counting at either the cognitive or the neural level (Balakrishnan \& Ashby, 1991, 1992; Piazza, Mechelli, Butterworth, \& Price, 2002). In particular, Balakrishnan and Ashby (1992) failed to find any statistical evidence in support of a discontinuity in response latencies between subitizing and counting in the analysis of a wide range of visual enumeration data. They concluded that the two processes are not, in fact, different in nature but instead simply reflect a continuum along a scale of increasing task difficulty (i.e., mental effort). The pattern of results obtained in the present study, which shows a lack of any robust difference between the subitizing and counting ranges in any experimental condition, would appear to support this view (at least for displays of the type used here).

\section{GENERAL DISCUSSION}

The first important result to emerge from Experiment 1 is that participants' performance in a visuotactile bimodal numerosity judgment task could not be predicted on the basis of an independent resources account. In particular, the accuracy of participants' bimodal numerosity judgments was worse than was predicted by the combined performance results obtained from the limitations derived when people were presented with unimodal visual and tactile stimulus displays. As Figures 5C and 5D clearly show, all of the data points representing participants' performance in the bimodal numerosity judgment condition were significantly below those predicted on the basis of the sum of performance results obtained for the relevant unimodal conditions. This outcome is fully compatible with the shared resource model highlighted earlier (see Figure 2, in which the predicted limitation of the shared resource model, represented on the right, is lower than the sum of the limitations of the single-sensory modalities, represented on the left).

This result does not appear to support the view that visual and tactile numerosity judgments are processed entirely independently (i.e., the idea that separate resources are accessed independently by visual and tactile numerosity judgments or, more generally, by stimuli presented to each sensory modality; cf. Martin, 1980; Wickens, 1980). Instead, the types of information (or resources) required to compute the number of visual and tactile stimuli presented in the display at any one time appear to interact with each other at some level of information processing. Our results go beyond earlier attempts to determine the locus of the bottleneck in making numerosity judgments (see Cheatham \& White, 1952; Harter \& White, 1967; White, 1963; White, Cheatham, \& Armington, 1953, for early attempts to elucidate the locus of the limitation in unimodal visual numerosity judgments) by suggesting that the point at which information processing constrains numerosity judgments is cross-modally constrained (i.e., the point of constraint occurs after the unimodal processing of information available to each sensory modality).

The most widely accepted explanation for the information processing limitations reported in previous studies of visual and tactile numerosity judgments relates to central mechanisms, or higher order levels of neural processing (see, e.g., Cowan, 2001; Fisher, 1984). In particular, limitations in focused attention, spatial attention, spatial representation, and stimulus representation/retention, as well as central masking, have all been proposed as explanations for the limitations observed (see, e.g., Alluisi et al., 1965; Chan \& Spence, 2006; Gallace et al., 2005; Gallace, Tan, \& Spence, 2006b; Hillstrom, Shapiro, \& Spence, 2002; Miller, 1956; Rensink, 2002). However, it is still unclear whether such mechanisms can be considered to be modality specific or amodal/multisensory (see Driver \& Spence, 2004).

A second relevant result to emerge from Experiment 1 is the lack of discontinuity in participants' numerosity judgments for bimodal displays. That is, participants' error rates increased linearly (see Table 4 for the functions that best fit the data) as the number of stimuli presented in the display increased, without showing the difference between the subitizing and counting ranges that is often reported in visual studies (see, e.g., Jensen et al., 1950; 
Kaufman et al., 1949; Mandler \& Shebo, 1982; Peterson \& Simon, 2000; Trick \& Pylyshyn, 1993; Wender \& Rothkegel, 2000; though see Balakrishnan \& Ashby, 1991, 1992, and Gallace et al., 2006d, for cautionary notes). This result therefore suggests that numerosity judgments for multisensory displays might be based on an analogue (i.e., continuous) form of numerical representation (see Cantlon \& Brannon, 2006; Dehaene \& Changeux, 1993; Gallace et al., 2006d; Nieder \& Miller, 2004a, 2004b; cf. Balakrishnan \& Ashby, 1991).

Dehaene and Changeux (1993) put forward a neural model for numerical abilities in humans based on analogue representations. According to their model, visual numerical information is processed at different computational stages. The first level of numerical information processing corresponds to a distribution of activation across topographically organized input clusters (e.g., in the case of visual stimuli, the retina). The input clusters project onto a location map, where the stimuli are coded according to their positions on the map, regardless of their physical qualities (such as size or code at the previous level of processing). The processing units of the location map project to the summation clusters. At this stage, numerical information is coded in terms of the total activity over all the positions of the location map. These clusters respond only when the total activity exceeds a certain threshold. The last stage of processing consists of the numerosity clusters. At this level of processing, different neuronal clusters respond only when their preferred numerosity is presented.

We believe that it might be possible to successfully adapt Dehaene and Changeux's (1993) model to take into account the results obtained in numerosity judgment tasks under conditions of multisensory stimulus presentation as reported here (see Figure 8). In particular, it seems plausible to think about the presence of different modalityspecific input clusters, all projecting to a common amodal/ multisensory location map. Whereas the information represented in the input clusters might be coded by means of modality-specific frames of reference (i.e., retinotopic for vision and somatotopic for touch), the number of inputs in the location map might instead be coded to a modalitynonspecific spatial frame of reference (perhaps body or space centered).

The processing limitations of the more peripheral stages of the model may be different for each sensory modality, which may account, for example, for the better performance obtained with visual than with tactile unimodal numerosity judgment tasks (cf. Gallace et al., 2006c). A further peripheral stage of processing, the memory clusters, in which units with recurrent connections keep a longer lasting activity, would represent the short-term sensory memory storage systems for each modality. At this stage of processing, limitations might also be different for the different sensory modalities. We believe that such a multisensory version of Dehaene and Changeux's (1993) model provides a plausible framework in which to interpret the results of our experiments, in terms of processing limitations affecting the central amodal/multisensory location map.

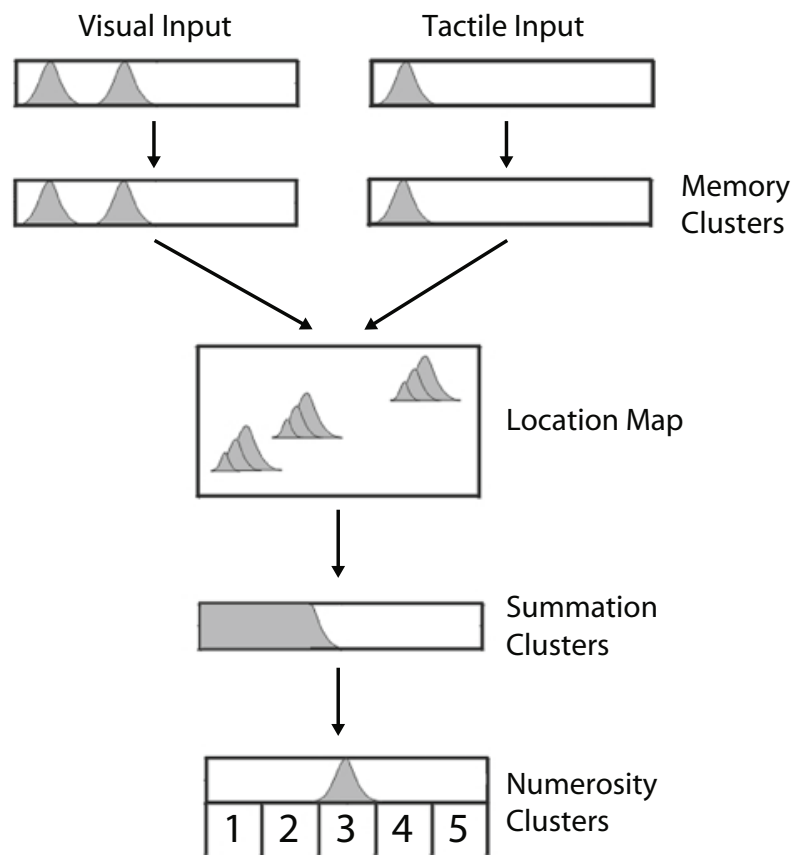

Figure 8. Structure of the proposed multisensory numerosity detection model. Input from different sensory modalities is normalized and represented by means of a spatial code on the location map. The activations across the location map are then added, resulting in an estimate of the number of stimuli presented in the display regardless of the sensory modality of their presentation. From "Development of Elementary Numerical Abilities: A Neural Model," by S. Dehaene and J. P. Changeux, 1993, Journal of Cognitive Neuroscience, 5, pp. 390-407. Adapted and extended with permission.

The results of Experiment 2 show that the poorer performance obtained when participants were presented with bimodal displays in comparison with unimodal displays cannot be accounted for on the basis of differences in focused attention versus attention divided among different sensory modalities, since the same number of enumeration errors was reported in both conditions. The lack of any effect of the focused versus divided attention manipulation in our study might be related to the unspeeded nature of the participant's task (cf. Spence, Nicholls, \& Driver, 2001; Spence, Shore, \& Klein, 2001). Alternatively, however, the explanation for the poorer performance obtained with bimodal displays in Experiment 1 might also relate to structural limitations (e.g., limitations related to processing or capacity limitations in multisensory or amodal systems that represent spatial information; see Spence, McDonald, \& Driver, 2004) affecting the number of stimuli that can be accessed by consciousness at any one time.

It has been proposed that competition among stimuli in terms of their ability to attract attention or elicit consciousness may occur at many different levels of information processing (i.e., neural representation) and that capacity limitations may be different at the various different levels of representation (i.e., limitations may increase moving from the periphery toward more central processing systems; see VanRullen \& Koch, 2003). The 
results obtained from single-cell recordings in monkeys (see, e.g., Rizzolatti, Scandolara, Matelli, \& Gentilucci, 1981), neuropsychological studies of brain-damaged patients (see, e.g., di Pellegrino, Làdavas, \& Farnè, 1997; Làdavas, di Pellegrino, Farnè, \& Zeloni, 1998; Mattingley, Driver, Beschin, \& Robertson, 1997), neuroimaging studies (see, e.g., Macaluso \& Driver, 2001; see Macaluso \& Driver, 2004a, 2004b, for recent reviews), and behavioral data (see, e.g., Farnè, Rossetti, Toniolo, \& Làdavas, 2002) all converge on the suggestion that the neural representation of peripersonal (or near peripersonal) space is multisensorially determined (see Driver \& Spence, 2004, for a recent review). Therefore, it is possible that when stimuli presented from different spatial positions fail to secure a certain level of activation within a multisensory/amodal spatial representation (i.e., the location map in the proposed model; see Figure 8), rather than across separate unisensory systems (cf. Desimone \& Duncan, 1995), this failure may result in a lack of conscious access to information regarding such stimuli. This failure might be attributed to the competition that may exist among stimuli presented from different positions at the same time (see, e.g., Gallace et al., 2006b; Wright, Green, \& Baker, 2000; cf. Desimone \& Duncan, 1995; VanRullen \& Koch, 2003), regardless of the sensory modality of the stimuli's presentation (see Hubbard et al., 2005, for the suggestion of an inextricable link between the neural substrates representing numerical and spatial information).

Clearly, future research should further investigate the role of spatial processing on multisensory numerosity judgments. In particular, it would be of interest to study numerosity judgments for audiovisual and audiotactile combinations of stimuli rather than just for the visuotactile combination studied here. Indeed, whereas tactile and visual numerosity judgments have both been shown to be based on spatial attributes of the stimuli, auditory numerosity judgments have been shown to rely on nonspatial attributes of the stimuli, such as the pitch of the sounds presented (see, e.g., Kubovy, 1981; see also Bedford, 2004).

The results of the two experiments reported here clearly show that, at the level of processing responsible for the limitation that affects numerosity judgments, the processing of visual and tactile stimuli interact in a way that adversely affects human performance. This interaction might be interpreted as the result of a higher order multisensory/amodal mechanism accessed by different sensory modalities and limited in the amount of information that can be effectively processed, that can have access to consciousness, or that can activate a specific response at any one time. Further studies should be conducted to determine which, if any, of the proposed possible higher level mechanisms might account for the observed limitations in human performance reported here. However, the results of the present study suggest that amodal limitations in spatial processing (see, e.g., Gallace, Auvray, et al., 2006; Gallace et al., 2005; Spence \& Driver, 2004) or central masking (see, e.g., Alluisi et al., 1965) might provide a valid explanation for the results of multisensory numerosity judgment studies. Note that the results of Ex- periment 2 show that focused attention did not have any modulatory effect on numerosity judgment performance.

It might be that there is a per-item cost in processing the number of stimuli in the displays that increases as soon as the number of stimuli presented increases above one. This cost might be little affected by whether one or two sensory modalities are being processed. Although this interpretation once again suggests that processing resources for numerosity judgments are shared among sensory modalities (and/or that numerosity judgments occur at higher levels of information processing; cf. White et al., 1953), visual inspection of Figure 5F suggests that this is not the case in the present study. Indeed, the results clearly show that there is a large cost, in terms of errors, when even a single visual item in a display is replaced by a single tactile element.

In the last few years, a large body of research has addressed the use and design of tactile interfaces for human operators in various applied settings (see, e.g., Ho, Tan, \& Spence, 2005; Rochlis \& Newman, 2000; Sorkin, 1987; Spence \& Driver, 1999; Tan, Gray, Young, \& Traylor, 2003; van Erp \& van Veen, 2003, 2004; see Gallace, Tan, \& Spence, 2006a, for a recent review). This interest appears to be related, at least in part, to the fact that the visual and auditory modalities may be overloaded in many real-world interface settings (see, e.g., Sorkin, 1987; van Veen \& van Erp, 2001), and the tactile modality has been suggested as a valid alternative for presenting relevant information to an interface operator (Hennessy, 1966). However, the results of the experiments reported here show that people's ability to process information in one sensory modality is not independent of their ability to process the information presented (or assess the number of stimuli) in another sensory modality, contrary to many widely believed models of interface design (see, e.g., Wickens, 1992; Wickens \& Liu, 1988).

The fact that limitations on information processing are, in some cases, amodal or multisensory imposes important constraints on the development of multisensory interfaces (cf. Reese, Reese, Volkman, \& Corbin, 1953, and Reese, Robinson, Stevenson, \& Volkman, 1960, for early research in this area). Using different modalities in a redundant manner (i.e., using stimuli in different modalities to carry the same informational content) should improve human operator performance. However, when the information carried by two (or more) sensory modalities is nonredundant (as in the present study), severe limitations may arise. The fact that the performance obtained with unimodal presentation cannot predict performance in bimodal displays merits serious consideration in the field of haptic display design. Indeed, in ecologically valid interface settings, the information presented is often, if not always, multisensory in nature.

\section{AUTHOR NOTE}

A.G. was supported by a grant from the Università degli Studi di Milano-Bicocca, Italy. H.Z.T. and C.S. were supported by a network grant from the Oxford McDonnell-Pew Centre for Cognitive Neuroscience. Correspondence regarding this article should be addressed to 
A. Gallace, Room B121, Department of Experimental Psychology, University of Oxford, Oxford, OX1 3UD England (e-mail: alberto.gallace@ psy.ox.ac.uk).

\section{REFERENCES}

Alluisi, E. A., Morgan, B. B., Jr., \& Hawkes, G. R. (1965). Masking of cutaneous sensations in multiple stimulus presentations. Perceptual \& Motor Skills, 20, 39-45.

Atkinson, J., Campbell, F. W., \& Francis, M. R. (1976). The magic number $4 \pm 0$ : A new look at visual numerosity judgements. Perception, 5, 327-334.

Atkinson, J., Francis, M. R., \& CAmpbell, F. W. (1976). The dependence of the visual numerosity limit on orientation, colour, and grouping in the stimulus. Perception, 5, 335-342.

Balakrishnan, J. D., \& Ashby, F. G. (1991). Is subitizing a unique numerical ability? Perception \& Psychophysics, 50, 555-564.

Balakrishnan, J. D., \& AshbY, F. G. (1992). Subitizing: Magical numbers or mere superstition? Psychological Research, 54, 80-90.

BEDFORD, F. L. (2004). Analysis of a constraint on perception, cognition, and development: One object, one place, one time. Journal of Experimental Psychology: Human Perception \& Performance, 30, 907-912.

Bertelson, P., \& DE Gelder, B. (2004). The psychology of multimodal perception. In C. Spence \& J. Driver (Eds.), Crossmodal space and crossmodal attention (pp. 151-177). New York: Oxford University Press.

Cantlon, J. F., \& Brannon, E. M. (2006). Shared system for ordering small and large numbers in monkeys and humans. Psychological Science, 17, 401-406.

Chan, J. S., \& Spence, C. (2006). Change deafness: An auditory analogue of visual change blindness? Manuscript submitted for publication.

Cheatham, P. G., \& White, C. T. (1952). Temporal numerosity: I. Perceived number as a function of flash number and rate. Journal of Experimental Psychology, 44, 447-451.

Cheatham, P. G., \& White, C. T. (1954). Temporal numerosity: III. Auditory perception of number. Journal of Experimental Psychology, 47, 425-428

Chen, L. M., Friedman, R. M., \& Roe, A. W. (2003). Optical imaging of a tactile illusion in area $3 \mathrm{~b}$ of the primary somatosensory cortex. Science, 302, 881-885.

Church, R. M., \& Meck, W. H. (1984). The numerical attribute of stimuli. In H. L. Roitblat, T. G. Bever, \& H. S. Terrace (Eds.), Animal cognition (pp. 445-464). Hillsdale, NJ: Erlbaum.

Colavita, F. B. (1974). Human sensory dominance. Perception \& Psychophysics, 16, 409-412.

Cowan, N. (2001). The magical number 4 in short-term memory: A reconsideration of mental storage capacity. Behavioral \& Brain Sciences, 24, 87-114.

Dehaene, S., \& Changeux, J.-P. (1993). Development of elementary numerical abilities: A neuronal model. Journal of Cognitive Neuroscience, 5, 390-407.

Desimone, R., \& Duncan, J. (1995). Neural mechanisms of selective visual attention. Annual Review of Neuroscience, 18, 193-222.

di Pellegrino, G., LÀdavas, E., \& Farnè, A. (1997). Seeing where your hands are. Nature, $\mathbf{3 8 8}, 730$.

Driver, J., \& Spence, C. (1998). Attention and the crossmodal construction of space. Trends in Cognitive Sciences, 2, 254-262.

Driver, J., \& SPENCE, C. (2004). Crossmodal spatial attention: Evidence from human performance. In C. Spence \& J. Driver (Eds.), Crossmodal space and crossmodal attention (pp. 179-220). New York: Oxford University Press.

DunCan, J., Martens, S., \& WARD, R. (1997). Restricted attentional capacity within but not between sensory modalities. Nature, 387, 808-810.

Eger, E., Sterzer, P., Russ, M. O., Giraud, A.-L., \& Kleinschmidt, A. (2003). A supramodal number representation in human intraparietal cortex. Neuron, 37, 719-725.

Farnè, A., Rossetti, Y., Toniolo, S., \& Làdavas, E. (2002). Ameliorating neglect with prism adaptation: Visuo-manual and visuo-verbal measures. Neuropsychologia, 40, 718-729.

FISHER, D. L. (1984). Central capacity limits in consistent mapping, visual search tasks: Four channels or more? Cognitive Psychology, 16, 449-484.

FoDOR, J. (1983). The modularity of mind. Cambridge, MA: MIT Press. Gallace, A., Auvray, M., Tan, H. Z., \& Spence, C. (2006). When vi- sual transients impair tactile change detection: A novel case of crossmodal change blindness? Neuroscience Letters, 398, 280-285.

Gallace, A., \& SPEnce, C. (2005). Visual capture of apparent limb position influences tactile temporal order judgments. Neuroscience Letters, 379, 63-68

Gallace, A., Tan, H. Z., \& Spence, C. (2005). Tactile change detection. Proceedings of the First World Haptic Conference, 1, 12-16.

Gallace, A., Tan, H. Z., \& Spence, C. (2006a). The body surface as a communication system: The state of the art after 50 years of research. Manuscript submitted for publication.

Gallace, A., Tan, H. Z., \& Spence, C. (2006b). The failure to detect tactile change: A tactile analogue of visual change blindness. Psychonomic Bulletin \& Review, 13, 300-303.

Gallace, A., Tan, H. Z., \& Spence, C. (2006c). Numerosity judgments for tactile stimuli distributed over the body surface. Perception, $\mathbf{3 5}$, 247-266.

Gallace, A., Tan, H. Z., \& Spence, C. (2006d). Subitizing in touch: Myth or reality? Manuscript submitted for publication.

Gardner, E. P., \& SPEncer, W. A. (1972). Sensory funneling: II. Cortical neuronal representation of patterned cutaneous stimuli. Journal of Neurophysiology, 35, 954-977.

GARNER, W. R. (1951). The accuracy of counting repeated short tones. Journal of Experimental Psychology, 41, 310-316.

Geldard, F. A., \& Sherrick, C. E., JR. (1965). Multiple cutaneous stimulation: The discrimination of vibratory patterns. Journal of the Acoustical Society of America, 37, 797-801.

Harter, M. R., \& White, C. T. (1967). Perceived number and evoked cortical potentials. Science, 156, 179-186.

Hein, G., Parr, A., \& Duncan, J. (2006). Within-modality and crossmodality attentional blinks in a simple discrimination task. Perception \& Psychophysics, 68, 54-61.

Hennessy, J. R. (1966). Cutaneous sensitivity communications. Human Factors, 8, 463-469.

HiLl, J. W. (1971). Processing of tactual and visual point stimuli sequentially presented at high rates. Journal of Experimental Psychology, 88, 340-348.

Hillstrom, A. P., Shapiro, K. L., \& Spence, C. (2002). Attention in processing sequentially presented vibrotactile targets. Perception \& Psychophysics, 64, 1068-1082.

Ho, C., TAN, H. Z., \& SPEnCE, C. (2005). Using spatial vibrotactile cues to direct a driver's visual attention. Transportation Research Part F: Traffic Psychology \& Behaviour, 8, 397-412.

Hubbard, E. M., Piazza, M., Pinel, P., \& Dehaene, S. (2005). Interactions between number and space in parietal cortex. Nature Reviews Neuroscience, 6, 435-448.

Jensen, E. M., Reese, E. P., \& Reese, T. W. (1950). The subitizing and counting of visually presented fields of dots. Journal of Psychology, 30, 363-392.

Jevons, W. S. (1871). The power of numerical discrimination. Nature, 3, 281-282.

JoRdAN, K. E., \& Brannon, E. M. (2006). The multisensory representation of number in infancy. Proceedings of the National Academy of Sciences, 103, 3486-3489.

Jordan, K. E., Brannon, E. M., Logothetis, N. K., \& GhaZanfar, A. A. (2005). Monkeys match the number of voices they hear to the number of faces they see. Current Biology, 15, 1034-1038.

Kashino, M., \& Hirahara, T. (1996). One, two, many — Judging the number of concurrent talkers. Journal of the Acoustical Society of America, 99, 2596-2603.

Kaufman, E., Lord, M., Reese, T., \& Volkmann, J. (1949). The discrimination of visual number. American Journal of Psychology, 62, 498-525.

Kobayashi, T., Hiraki, K., \& Hasegawa, T. (2005). Auditory-visual intermodal matching of small numerosities in 6-month-old infants. Developmental Science, 8, 409-419.

Kubovy, M. (1981). Concurrent-pitch segregation and the theory of indispensable attributes. In M. Kubovy \& J. R. Pomerantz (Eds.), Perceptual organization (pp. 55-96). Hillsdale, NJ: Erlbaum.

Làdavas, E., di Pellegrino, G., Farnè, A., \& Zeloni, G. (1998). Neuropsychological evidence of an integrated visuotactile representation of peripersonal space in humans. Journal of Cognitive Neuroscience, 10, 581-589.

Lakatos, S., \& Shepard, R. N. (1997). Time-distance relations in 
shifting attention between locations on one's body. Perception \& Psychophysics, 59, 557-566.

LECHELT, E. C. (1971). Spatial numerosity discrimination as contingent upon sensory and extrinsic factors. Perception \& Psychophysics, 10, 180-184.

LeChelt, E. C. (1974). Pulse number discrimination in tactile spatiotemporal patterns. Perceptual \& Motor Skills, 39, 815-822.

LECHELT, E. C. (1975). Temporal numerosity discrimination: Intermodal comparisons revisited. British Journal of Psychology, 66, 101-108.

Macaluso, E., \& Driver, J. (2001). Spatial attention and crossmodal interactions between vision and touch. Neuropsychologia, 39, 1304-1316.

Macaluso, E., \& Driver, J. (2004a). Functional imaging of crossmodal spatial representations and crossmodal spatial attention. In C. Spence \& J. Driver (Eds.), Crossmodal space and crossmodal attention (pp. 247-276). New York: Oxford University Press.

Macaluso, E., \& Driver, J. (2004b). Spatial representations and crossmodal interactions in the human brain. In G. A. Calvert, C. Spence, \& B. E. Stein (Eds.), Handbook of multisensory processing (pp. 529548). Cambridge, MA: MIT Press.

Mandler, G., \& Shebo, B. J. (1982). Subitizing: An analysis of its component processes. Journal of Experimental Psychology: General, $111,1-22$.

Maravita, A., Spence, C., Sergent, C., \& Driver, J. (2002). Seeing your own touched hands in a mirror modulates cross-modal interactions. Psychological Science, 13, 350-355.

Martin, M. (1980). Attention to words in different modalities: Fourchannel presentation with physical and semantic selection. Acta Psychologica, 44, 99-115.

Mattingley, J. B., Driver, J., Beschin, N., \& Robertson, I. H. (1997). Attentional competition between modalities: Extinction between touch and vision after right hemisphere damage. Neuropsychologia, 35, 867-880.

McComb, K. E., Packer, C., \& Pusey, A. E. (1994). Roaring and numerical assessment in contests between groups of female lions, Panthera leo. Animal Behaviour, 47, 379-387.

Miller, G. A. (1956). The magical number seven, plus or minus two: Some limits on our capacity for processing information. Psychological Review, 63, 81-97.

Navon, D., \& Gopher, D. (1979). On the economy of the humanprocessing system. Psychological Review, 86, 214-255.

Nieder, A. (2004). The number domain - Can we count on parietal cortex? Neuron, 44, 407-409.

Nieder, A., \& Miller, E. K. (2004a). Analog numerical representations in rhesus monkeys: Evidence for parallel processing. Journal of Cognitive Neuroscience, 16, 889-901.

Nieder, A., \& Miller, E. K. (2004b). A parieto-frontal network for visual numerical information in the monkey. Proceedings of the $\mathrm{Na}$ tional Academy of Sciences, 101, 7457-7462.

Peterson, S., \& Simon, T. J. (2000). Computational evidence for the subitizing phenomenon as an emergent property of the human cognitive architecture. Cognitive Science, 24, 93-122.

Piazza, M., Mechelli, A., Butterworth, B., \& Price, C. J. (2002). Are subitizing and counting implemented as separate or functionally overlapping processes? NeuroImage, 15, 435-446.

PoseY, T. B., \& James, M. R. (1976). Numerosity discrimination of tactile stimuli. Perceptual \& Motor Skills, 42, 671-674.

Posner, M. I. (1980). Orienting of attention. Quarterly Journal of Experimental Psychology, 32, 3-25.

Pylyshyn, Z. W., \& Storm, R. W. (1988). Tracking multiple independent targets: Evidence for a parallel tracking mechanism. Spatial Vision, 3, 179-197.

Reese, E. P., Reese, T. W., Volkman, J., \& Corbin, H. H. (1953). Psychophysical research, summary report. 1946-1952. Technical Report: SPECDEVCEN (131-1-5).

Reese, E. P., Robinson, H. B., Stevenson, J. G., \& Volkman, J. (1960). Relative effectiveness of presenting information to selected sense modalities. Technical Report: NAVTRADEVCEN (512-1).

Rensink, R. A. (2002). Change detection. Annual Review of Psychology, 53, 245-277.

Riggs, K. J., Ferrand, L., Lancelin, D., Fryziel, L., Dumur, G., \& Simpson, A. (2006). Subitizing in tactile perception. Psychological Science, 17, 271-275.

Rizzolatti, G., Scandolara, C., Matelli, M., \& Gentilucci, M.
(1981). Afferent properties of periarcuate neurons in macaque monkeys: I. Somatosensory responses. Behavioural Brain Research, 2, 125-146.

Rochlis, J. L., \& Newman, D. J. (2000). A tactile display for international space station (ISS) extravehicular activity (EVA). Aviation, Space, \& Environmental Medicine, 71, 571-578.

Sathian, K., Greenspan, A. I., \& Wolf, S. L. (2000). Doing it with mirrors: A case study of a novel approach to neurohabilitation. Neurohabilitation \& Neural Repair, 14, 73-76.

Sinnett, S., Spence, C., \& Soto-Faraco, S. (in press). Visual dominance and attention: The Colavita effect revisited. Perception \& Psychophysics.

SorkIN, R. D. (1987). Design of auditory and tactile displays. In G. Salvendy (Ed.), Handbook of human factors (pp. 549-576). New York: Wiley.

Soto-Faraco, S., \& Spence, C. (2002). Modality-specific auditory and visual temporal processing deficits. Quarterly Journal of Experimental Psychology, 55A, 23-40.

SPEnCE, C., \& Driver, J. (1999). Multiple resources and multimodal interface design. In D. Harris (Ed.), Engineering psychology and cognitive ergonomics. Vol. 3: Transportation systems, medical ergonomics and training (pp. 305-312). Hampshire, U.K.: Ashgate.

Spence, C., \& Driver, J. (EDs.) (2004). Crossmodal space and crossmodal attention. New York: Oxford University Press.

Spence, C., McDonald, J., \& Driver, J. (2004). Exogenous spatialcuing studies of human crossmodal attention and multisensory integration. In C. Spence \& J. Driver (Eds.), Crossmodal space and crossmodal attention (pp. 277-320). New York: Oxford University Press.

Spence, C., Nicholls, M. E. R., \& Driver, J. (2001). The cost of expecting events in the wrong sensory modality. Perception \& Psychophysics, 63, 330-336.

Spence, C., Pavani, F., \& Driver, J. (2004). Spatial constraints on visual-tactile crossmodal distractor congruency effects. Cognitive, Affective, \& Behavioral Neuroscience, 4, 148-169.

Spence, C., Shore, D. I., \& Klein, R. M. (2001). Multisensory prior entry. Journal of Experimental Psychology: General, 130, 799-832.

Starkey, P., Spelke, E. S., \& Gelman, R. (1990). Numerical abstraction by human infants. Cognition, 36, 97-128.

Tan, H. Z., Gray, R., Young, J. J., \& Traylor, R. (2003). A haptic back display for attentional and directional cueing. Haptics-e: The Electronic Journal of Haptics Research, 3, MS 2002-07. Retrieved from www.haptics-e.org/vol_03/index.html.

Taubman, R. E. (1950). Studies in judged number: I. The judgment of auditory number. Journal of General Psychology, 43, 167-194.

TEN Hoopen, J., \& Vos, J. (1979). Effect on numerosity judgment of grouping of tones by auditory channels. Perception \& Psychophysics, 26, 374-380.

Trick, L. M., \& Pylyshyn, Z. W. (1993). What enumeration studies can show us about spatial attention: Evidence for limited capacity preattentive processing. Journal of Experimental Psychology: Human Perception \& Performance, 12, 331-351.

TRICK, L. M., \& PYLYshyn, Z. W. (1994). Why are small and large numbers enumerated differently? A limited-capacity preattentive stage in vision. Psychological Review, 101, 80-102.

Vallar, G., Rusconi, M. L., Bignamini, L., Geminiani, G., \& Perani, D. (1994). Anatomical correlates of visual and tactile extinction in humans: A clinical CT scan study. Journal of Neurology, Neurosurgery, \& Psychiatry, 57, 464-470.

van ERP, J. B. F., \& van Veen, H. A. H. C. (2003). A multi-purpose tactile vest for astronauts in the international space station. In Proceedings of Eurohaptics 2003 (pp. 405-408). Dublin: Trinity College.

van ERP, J. B. F., \& van Veen, H. A. H. C. (2004). Vibrotactile invehicle navigation system. Transportation Research Part F: Traffic Psychology \& Behaviour, 7, 247-256.

VANRullen, R., \& КосH, C. (2003). Competition and selection during visual processing of natural scenes and objects. Journal of Vision, $\mathbf{3}$, $75-85$.

van Veen, H. A. H. C., \& van ErP, J. B. F. (2001). Tactile information presentation in the cockpit. In S. Brewster \& R. Murray-Smith (Eds.), Haptic human-computer interaction (pp. 174-181). Berlin: Springer. Vitevitch, M. S. (2003). Change deafness: The inability to detect changes between two voices. Journal of Experimental Psychology: Human Perception \& Performance, 29, 333-342. 
ViVIANi, P. (1979). Choice reaction times for temporal numerosity. Journal of Experimental Psychology: Human Perception \& Performance, 5, 157-167.

VON BÉKÉSY, G. (1959). Neural funneling along the skin and between the inner and outer hair cells of the cochlea. Journal of the Acoustical Society of America, 31, 1236-1249.

Vuilleumier, P. O., \& Rafal, R. D. (2000). A systematic study of visual extinction: Between- and within-field deficits of attention in hemispatial neglect. Brain, 123, 1263-1279.

WEISs, W. (1965). Influence of an irrelevant stimulus attribute on numerosity judgments. Perceptual \& Motor Skills, 21, 404.

Wender, K. F., \& Rothkegel, R. (2000). Subitizing and its subprocesses. Psychological Research, 64, 81-92.

White, C. T. (1963). Temporal numerosity and the psychological unit of duration. Psychological Monographs, 77, 1-37.

White, C. T., \& Cheatham, P. G. (1959). Temporal numerosity: IV. A comparison of the major senses. Journal of Experimental Psychology, $\mathbf{5 8}, 441-444$

White, C. T., Cheatham, P. G., \& Armington, J. C. (1953). Temporal numerosity: II. Evidence for central factors influencing perceived number. Journal of Experimental Psychology, 46, 283-287.

Whiteley, L., Kennett, S., Taylor-Clarke, M., \& Haggard, P. (2004). Facilitated processing of visual stimuli associated with the body. Perception, 33, 307-314.
WiCKEnS, C. D. (1980). The structure of attentional resources. In R. S. Nickerson (Ed.), Attention and performance VIII (pp. 239-257). Hillsdale, NJ: Erlbaum.

WiCKENS, C. D. (1992). Engineering psychology and human performance. New York: HarperCollins.

WiCKENS, C. D. (2002). Multiple resources and performance prediction. Theoretical Issues in Ergonomic Science, 3, 159-177.

Wickens, C. D., \& LIU, Y. (1988). Codes and modalities in multiple resources: A success and a qualification. Human Factors, 30, 599-616.

Wright, M., Green, A., \& BaKer, S. (2000). Limitations for change detection in multiple Gabor targets. Visual Cognition, 7, 237-252.

\section{NOTE}

1. Sensory funneling occurs when two points on the skin are stimulated at the same time (e.g., on the palm, forearm, or fingers), and people sometimes report perceiving only a single tactile stimulus located somewhere between the two physically stimulated locations (see, e.g., Chen, Friedman, \& Roe, 2003; Gardner \& Spencer, 1972).

(Manuscript received July 1, 2005; revision accepted for publication August 14, 2006.) 